\title{
Role of radiotherapy in metastatic non-small cell lung
}

\section{cancer}

\section{Sergio L. Faria*}

Department of Radiation Oncology, McGill University Health Centre, Montreal General Hospital, Montreal, QC, Canada

Edited by:

Vera Hirsh, McGill University Health

Centre, Canada

\section{Reviewed by:}

Heloisa De Andrade Carvalho, Hospital das Clínicas da Faculdade de Medicina da Universidade de São

Paulo, Brazil

Bo H. Chao, The Ohio State

University, USA

*Correspondence:

Sergio L. Faria, Department of Radiation Oncology, MGH, McGill

University Health Centre, 1650 Cedar

Av, room D5.400, Montreal, OC

H3G1A4, Canada

e-mail: sergio.faria@muhc.mcgill.ca
Radiotherapy has had important role in the palliation of NSCLC. Randomized trials tend to suggest that, in general, short regimens give similar palliation and toxicity compared to longer regimens. The benefit of combining chemotherapy to radiosensitize the palliative radiation treatment is an open question, but so far it has not been proved to be very useful in NSCLC. The addition of molecular targeted drugs to radiotherapy outside of approved regimens or clinical trials warrants careful consideration for every single case and probably should not be used as a routine management. Stereotactic radiosurgery (SRS) and stereotactic body radiation therapy (SBRT) are modern techniques being used each time more frequently in the treatment of single or oligometastases. In general, they offer good tumor control with little toxicity (with a more expensive cost) compared to the traditionally fractionated radiotherapy regimens.

Keywords: palliative radiotherapy, metastatic NSCLC, stereotactic body radiosurgery, radiosensitizers

\section{INTRODUCTION}

Good palliative local treatment should be simple, fast, generally efficient, and not very expensive. Radiotherapy has largely been used to palliate NSCLC for all these reasons (1). A good example is the fact that one simple treatment of external beam radiation treatment (EBRT) may stop a hemoptysis. Multiple prospective randomized trials using different dose/fractionation schedules have shown that palliative radiotherapy can often alleviate thoracic and extra-thoracic symptoms in patients with locally advanced or metastatic NSCLC (1-3).

Indications for thoracic EBRT include, but are not limited to: hemoptysis, cough, chest pain, dyspnea, obstructive pneumonia, dysphagia related to esophageal compression, superior vena cava syndrome, hoarseness, or stridor. Symptoms caused by malignant pleural effusion, lymphangitic carcinomatosis, and multiple parenchymal diseases typically are not suitable for palliative thoracic EBRT.

Indications for extra-thoracic EBRT include, but are not limited to: brain, adrenal, bone, and liver metastases.

\section{REVIEWS}

In 2009, a comprehensive review involving 14 randomized clinical trials, all related to different dose schedules to palliate the symptomatic primary lung cancer, was performed by the Cochrane Collaboration (4). In general, the results of those trials suggest that there are not significant differences among short compared to long radiotherapy regimens in terms of palliation, but higherdose regimens were associated with mild increased acute toxicity, particularly esophagitis (Table 1). However, the studies are not homogeneous, the end points and assessments were different, and the reviewers did not make a clear conclusion on the ideal regimen of palliative radiation treatment. In fact, in clinical practice, depending on the institution, we have seen different doses and fractionations regimens being used for similar clinical situations. It is very well possible that, at least in part, remuneration directs practical management. The case for bone metastases is a good example. Despite a considerable body of evidence from randomized trials supporting the use of a single fraction of $8 \mathrm{~Gy}$ for radiation therapy, there is still considerable use of longer regimens such as $30 \mathrm{~Gy}$ in 10 fractions (5).

\section{TYPICAL PALLIATIVE RADIOTHERAPY DOSE AND FRACTIONATION IN NSCLC}

At the McGill University Health Centre (MUHC), we practice evidence-based medicine preferring short and simple treatments. Our typical palliative dose is $17 \mathrm{~Gy}$ in two fractions (1 week apart) after randomized trials concluded that this regimen is simple, well tolerated, and efficient compared to other regimens $(6,7)$.

\section{SVC SYNDROME}

In the past, SVC syndrome was considered a potentially lifethreatening medical emergency requiring immediate radiotherapy as the quickest way to relieve the obstruction. Emergency radiotherapy is no longer considered necessary for most patients (8). Patients who present with stridor due to central airway obstruction or severe laryngeal edema represent a true medical emergency, and these patients require immediate treatment (stent placement and/or radiotherapy) to decrease the risk of sudden respiratory failure and death. Evidence-based guidelines for management of SVC syndrome are not available. Most of the malignancies causing SVC syndrome, including NSCLC, are radiation-sensitive, and symptomatic improvement is usually apparent within $72 \mathrm{~h}$, associated with complete relief of symptoms of SVC obstruction in $63 \%$ of patients with NSCLC (9). Radiotherapy treatments are typically 
Table 1 | Randomized controlled trials assessing palliative lung radiotherapy fractionation [from Ref. (3)]

\begin{tabular}{|c|c|c|c|c|c|}
\hline Study & Year & Radiotherapy schedules compared & $\begin{array}{l}\text { Evaluable } \\
\text { patients }(n)\end{array}$ & $\begin{array}{l}\text { Survival }{ }^{\mathrm{a}} \text { by regimen } \\
(P=\mathrm{NS} \text { unless specified })\end{array}$ & $\begin{array}{l}\text { Symptom control by regimen } \\
(P=\text { NS unless specified })\end{array}$ \\
\hline Simpson & 1985 & $\begin{array}{l}40 \mathrm{~Gy} / 20 \mathrm{~F} \text { daily continuous/4 weeks vs. } \\
30 \mathrm{~Gy} / 10 \mathrm{~F} / 2 \text { weeks vs. } 40 \mathrm{~Gy} / 10 \mathrm{~F} / 4 \text { weeks, } \\
\text { split course }\end{array}$ & 316 & 6.2 vs. 6.9 vs. 6.4 months & No difference \\
\hline Teo & 1988 & $45 \mathrm{~Gy} / 18 \mathrm{~F} / 3.5$ weeks vs. $31.2 \mathrm{~Gy} / 4 \mathrm{~F} / 4$ weeks & 273 & 20 vs. 20 weeks & Better with $45 \mathrm{~Gy}, P=0.012$ \\
\hline MRC & 1992 & $17 \mathrm{~Gy} / 2 \mathrm{~F} / 8$ days vs. $10 \mathrm{~Gy} / 1$ fraction & 235 & 100 vs. 122 days & No difference \\
\hline Abratt & 1995 & $\begin{array}{l}35 \mathrm{~Gy} / 10 \mathrm{~F} / 2.5 \text { weeks vs. } \\
45 \mathrm{~Gy} / 15 \mathrm{~F} / 3.75 \text { weeks }\end{array}$ & 84 & 8.5 vs. 8.5 months & No difference \\
\hline Reinfuss & 1999 & $\begin{array}{l}50 \mathrm{~Gy} / 25 \mathrm{~F} / 5 \text { weeks (conventional) vs. } \\
40 \mathrm{~Gy} / 10 \mathrm{~F} \text { daily (split course with } 4 \text { weeks } \\
\text { gap) vs. delayed radiotherapy ( } 2025 \mathrm{~Gy} / 4 \text { or } \\
5 \mathrm{~F} \text { when symptomatic). }\end{array}$ & 240 & $\begin{array}{l}18 \text { vs. } 6 \text { vs. } 0 \%, P<0.05 \\
\text { ( } 2 \text { years) }\end{array}$ & No assessment of symptoms \\
\hline Nestle & 2000 & $\begin{array}{l}32 \mathrm{~Gy} / 16 \mathrm{~F} \text { twice daily/10 days vs. } 60 \mathrm{~Gy} / 30 \\
\text { F/6 weeks }\end{array}$ & 152 & 36 vs. $38 \%$ ( 1 year) & No difference \\
\hline Bezjak & 2002 & $20 \mathrm{~Gy} / 5 \mathrm{~F} / 1$ weeks vs. $10 \mathrm{~Gy} / 1 \mathrm{~F}$ & 230 & 6 vs. 4.2 months, $P=0.03$ & $\begin{array}{l}\text { Better for } 20 \text { Gy on Lung Cancer } \\
\text { Symptom Scale, } P=0.009\end{array}$ \\
\hline Sundstrom & 2004 & $\begin{array}{l}17 \mathrm{~Gy} / 2 \mathrm{~F} / 8 \text { days vs. } 42 \mathrm{~Gy} / 15 \mathrm{~F} / 3 \text { weeks vs. } \\
50 \mathrm{~Gy} / 25 \mathrm{~F} / 5 \text { weeks }\end{array}$ & 407 & 6.8 vs. 7.0 vs. 8.2 months & No difference \\
\hline
\end{tabular}

F, fraction; Gy, gray; NS, non-significant.

a Survival given as median value or percentage at specific timepoint.

administered over a course of 1-2 weeks with larger fraction sizes of 3-8 Gy (e.g., 17 Gy in 2 fractions, 20 Gy in 5 fractions, and 30 Gy in 10 fractions), with the goal of achieving a more rapid response by using larger daily doses (10).

\section{BRACHYTHERAPY}

In our Department at MUHC, we have the facilities to use high dose rate (HDR) endobronchial brachytherapy for palliation of hemoptysis or obstruction (we use doses between 6 and $10 \mathrm{~Gy}$ at $1 \mathrm{~cm}$ ). Brachytherapy has been used sporadically. Comparing brachytherapy to EBRT is difficult. There is currently no randomized or meta-analysis based evidence to recommend endobronchial brachytherapy as the routine initial palliative management of endobronchial obstruction resulting from lung cancer (11).
The use of concurrent chemotherapy with palliative irradiation in lung cancer.

The question if some systemic treatment should be used as a radiosensitizer of palliative radiotherapy in NSCLC is open for discussion. The question is pertinent because several randomized studies have demonstrated that, when compared with best supportive care, chemotherapy not only significantly improves survival but also reduces symptoms and enhances quality of life in stage IV NSCLC. However, in palliative radiotherapy the total dose is usually not very high (to avoid risk of radiation induced toxicity). In general, in the group of metastatic NSCLC patients that need local radiotherapy palliation, the addition of chemotherapy may increase toxicity, cost, and may complicate the delivery of the whole treatment without significant improved palliation. At this time, it seems that there is no added benefit for the use 
of chemotherapy concurrently with radiation therapy in the palliation of thoracic symptoms in lung cancer patients $(3,4)$, but this is of course an open topic and indications may be discussed in a case by case basis. There is only one randomized clinical trial addressing this issue showing that the use of continuousinfusion fluorouracil showed only a discrete better response but with increased toxicity in palliation of NSCLC (12). However, fluorouracil is not an agent currently used in NSCLC, and the available data of palliative radiotherapy with the use of other agents commonly used today as systemic treatment in NSCLC such as platinum based chemotherapy, vinorelbine, or gemcitabine, are not very persuasive $(13,14)$.

\section{THE USE OF TARGET AGENTS WITH PALLIATIVE RADIOTHERAPY}

When used in combination with radiotherapy, molecularly targeted agents aim to increase the effect of the radiation on the tumor. Substantial preclinical data have accumulated to show that these agents can potentially enhance the tumor response to radiotherapy through a variety of mechanisms (15). They offer new but challenging possibilities for clinical practice. There is a growing number of publications and reviews on the topic of combination of radiotherapy and targeted therapies in many cancers, including NSCLC $(16,17)$. The addition of targeted agents to thoracic radiation so far has not improved outcomes in patients with locally advanced NSCLC $(18,19)$.

The combination of radiotherapy and molecular agents targeting vascular endothelial growth factor (VEGF) mediated angiogenesis may evolve synergistic effects leading to enhanced tumor cell killing on the one hand, but to enhanced normal tissue damage on the other hand (20). To date, there are only limited data on the efficacy and toxicity of anti-angiogenic agents given in combination with radiotherapy in lung cancer.

Given the strong preclinical rationale for combining EGFR inhibitors (Cetuximab, Panitumumab, Erlotinib, Gefitinib, Lapatinib, and Trastuzumab) with radiation, additional studies are crucial. Phase I/II data and lack of long-term experience suggest that physicians should consider combined modality approaches with caution, considering the possibility of uncommon but potentially severe toxicity (21).

With high-precision irradiation techniques (such as "stereotactic body radiation therapy"), the combination with targeted agents is feasible with apparent no increase in severe adverse events. Nevertheless, the addition of molecular targeted drugs to radiotherapy outside of approved regimens or clinical trials warrants careful consideration for every single case.

The problem of timing is particular to radiotherapy and molecularly targeted agent combination research. It cannot be assumed that giving the drug concurrently with radiation (as it happens with chemotherapy) is always the optimal treatment strategy. Indeed, drugs that cause cell cycle arrest or prolong cells in the radio-resistant phase of the cell cycle may jeopardize the radiation effect (17).

\section{BRAIN METASTASES}

When brain metastases occur in patients with NSCLC, there is often also active disease at the primary site or elsewhere in the body. In few cases, the brain is the only site with active disease (22).

There are many guidelines on the treatment of brain metastases showing that therapeutic intervention (radiotherapy or surgery) is associated with improved brain control (23).

Stereotactic radiosurgery (SRS) to the brain involves a single shot of high dose radiotherapy and can control very efficiently one to few metastases either close to the surface or deep in the brain (24). No randomized trials compared SRS with traditional surgical resection. The traditional whole brain radiotherapy (WBRT) (that covers the whole brain) treats the metastases and may also prevent the growth of new metastases, but may cause side effects such as memory loss. Recent Cochrane review shows that there is low quality evidence that adding upfront WBRT to surgery or to SRS decreases any intracranial disease progression at 1 year. There is also no clear evidence of an effect on overall and progression free survival (25).

Stereotactic radiosurgery has become increasingly important treatment technique in the management of brain metastases, but it is not available everywhere and it is more expensive than WBRT. An approach of SRS alone as initial treatment of brain metastases has allowed patients to delay or avoid WBRT and its associated side effects. "One of the most critical questions on this topic is how "benefit" is defined and from who's perspective - patient, provider, payer, or society" (26). Whether the cost of SRS in multiple brain metastases versus just WBRT approach is justified has yet to be defined.

\section{STEREOTACTIC BODY RADIATION THERAPY}

Stereotactic body radiation therapy or "stereotactic ablative radiotherapy" (SART) is a technique similar to SRS, but used in tumors outside the brain. It utilizes precisely targeted high dose radiation to the tumor while minimizing radiation to adjacent normal tissue. It has the luxury of using 4D CT scans to manage the pulmonary motion during treatments. This technique allows treatment of small to moderate sized tumors, in either a single or limited number of high daily dose fractions, with high chances of local control and little toxicity. SBRT has a role in treating selected patients with painful bone metastases or with oligometastases in lungs, liver, or other sites. In spine metastases, for example, non-randomized data show good results with this technique (27). Radiation Therapy Oncology Group (RTOG) study number 0631 is an open Phase II/III Study of Image-Guided SBRT for localized spine metastasis comparing one treatment of 16 Gy delivered with SBRT versus a single fraction of $8 \mathrm{~Gy}(28)$.

In patients with NSCLC and with oligometastases, there is a trend to treat them with SBRT, although there is no evidencebased data to show that SBRT is better than traditional palliative radiotherapy. Recently, a proposal submitted to RTOG was not approved because many participants would consider abusive not to offer SBRT in those cases. There is no prospective randomized trial to answer this question. The COMET study (stereotactic ablative radiotherapy for comprehensive treatment of oligometastatic tumors (SABR-COMET) is a randomized Phase II Trial (PIs: David Palma, and Suresh Senan) open in Europe and Canada, comparing patients with up to five metastatic lesions from any primary tumor site who can receive SABR. Eligible patients are randomized to 
either standard palliative radiotherapy versus SABR (with further chemotherapy at discretion of medical oncologist).

\section{REFERENCES}

1. Okawara G, Mackay JA, Evans WK, Ung YC, Lung Cancer Disease Site Group of Cancer Care Ontario's Program in Evidence-based Care. Lung Cancer Disease Site Group of Cancer Care Ontario's program in evidence-based care. Management of unresected stage III non-small cell lung cancer: a systematic review. J Thorac Oncol (2006) 1:377-93. doi:10.1097/01243894-200605000-00019

2. National Comprehensive Cancer Network. Treatment Guidelines - NCCN Clinical Practice Guidelines in Oncology Non-Small Cell Lung Cancer V.2. (2010). Available from: http://www.nccn.org/professionals/physician_gls/PDF/ nscl.pdf

3. Rodrigues G, Videtic GM, Sur R, Bezjak A, Bradley J, Hahn CA, et al. Palliative thoracic radiotherapy in lung cancer: an American Society for Radiation Oncology evidence-based clinical practice guideline. Pract Radiat Oncol (2011) 1:60-71. doi:10.1016/j.prro.2011.01.005

4. Lester JF, Macbeth FR, Toy E, Coles B. Palliative radiotherapy regimens for non-small cell lung cancer. Cochrane Database Syst Rev (2006) (4):CD002143. doi:10.1002/14651858.CD002143.pub2

5. Kachnic L, Berk L. Palliative single-fraction radiation therapy: how much more evidence is needed? J Natl Cancer Inst (2005) 97:11. doi:10.1093/jnci/dji166

6. Sundstrøm S, Bremnes R, Aasebø U, Aamdal S, Hatlevoll R, Brunsvig P, et al. Hypofractionated palliative thoracic RT (17 Gy/2) in advanced NSCLC is comparable to standard fractionation for symptom control and survival. A national phase III trial. J Clin Oncol (2004) 22:801-10. doi:10.1200/JCO.2004.06.123

7. Cross CK, Berman S, Buswell L, Johnson B, Baldini EH. A prospective study of palliative hypofractionated radiation therapy ( $8.5 \mathrm{~Gy} \times 2$ ) for patients with symptomatic NSCLC. Int J Radiat Oncol Biol Phys (2004) 58(4):1098-105. doi:10.1016/j.ijrobp.2003.08.005

8. Schraufnagel DE, Hill R, Leech JA, Pare JA. Superior vena caval obstruction. Is it a medical emergency? Am J Med (1981) 70:1169. doi:10.1016/0002-9343(81) 90823-8

9. Rowell NP, Gleeson FV. Steroids, radiotherapy, chemotherapy and stents for superior vena caval obstruction in carcinoma of the bronchus: a systematic review. Clin Oncol (R Coll Radiol) (2002) 14:338. doi:10.1053/clon.2002.0095

10. Jonathan F, Wan AB. Superior vena cava syndrome. Review article. Hematol Oncol Clin North Am (2010) 24(3):501-13. doi:10.1016/j.hoc.2010.03.003

11. Ung YC, Yu E, Falkson C, Haynes AE, Stys-Norman D, Evans WK, et al. The role of high-dose-rate brachytherapy in the palliation of symptoms in patients with non-small cell lung cancer: a systematic review. Brachytherapy (2006) 5:189-202. doi:10.1016/j.brachy.2006.05.001

12. Ball D, Smith J, Bishop J, Olver I, Davis S, O’Brien P, et al. A phase III study of radiotherapy with and without continuous-infusion fluorouracil as palliation for non-small cell lung cancer. Br J Cancer (1997) 75:690-7. doi:10.1038/bjc. 1997.123

13. Hoffman PC, Cohen EE, Masters GA, Haraf DJ, Mauer AM, Rudin CM, et al. Carboplatin plus vinorelbine with concomitant radiation therapy in advanced nonsmall cell lung cancer. Lung Cancer (2002) 38:65-71. doi:10.1016/S01695002(02)00144-7

14. Choi B, Robins HI, Schiller J, Mehta M. A phase I study of gemcitabine plus palliative radiation therapy for advanced lung cancer. Cancer Chemother Pharmacol (2008) 63:175-9. doi:10.1007/s00280-008-0708-8

15. Lin SH, George TJ, Ben-Josef E, Bradley J, Choe KS, Edelman MJ, et al. Opportunities and challenges in the era of molecularly targeted agents and radiation therapy. J Nat Cancer Inst (2013) 105(10):686-93. doi:10.1093/jnci/djt055

16. Niyazi M, Maihoefer C, Krause M, Rödel C, Budach W, Belka C. Radiotherapy and "new" drugs-new side effects? Radiat Oncol (2011) 6:177. doi:10.1186/1748717X-6-177
17. Searle EJ, Illidge TM, Stratford IJ. Emerging opportunities for the combination of molecularly targeted drugs with radiotherapy. Clin Oncol ( $R$ Coll Radiol) (2014) 26(5):266-76. doi:10.1016/j.clon.2014.02.006

18. Spigel DR, Hainsworth JD, Yardley DA, Raefsky E, Patton J, Peacock N, et al. Tracheoesophageal fistula formation in patients with lung cancer treated with chemoradiation and bevacizumab. J Clin Oncol (2010) 28:43-8. doi:10.1200/ JCO.2009.24.7353

19. Sacco PC, Maione P, Rossi A, Bareschino MA, Schettino C, Guida C, et al. Combination of radiotherapy and targeted therapies in the treatment of locally advanced non-small cell lung cancer. Target Oncol (2011) 6(3):171-80. doi:10.1007/s11523-011-0169-6

20. Mazeron R, Anderson B, Supiot S, Paris F, Deutsch E. Current state of knowledge regarding the use of antiangiogenic agents with radiation therapy. Cancer Treat Rev (2011) 37:476-86. doi:10.1016/j.ctrv.2011.03.004

21. Xu Y, Zhang Y, Ma S. EGFR inhibitors with concurrent thoracic radiation therapy for locally advanced non-small cell lung cancer. Lung Cancer (2011) 73(3):249-55. doi:10.1016/j.lungcan.2011.04.017

22. Ashworth A, Rodrigues G, Boldt G, Palma D. Is there an oligometastatic state in non-small cell lung cancer? A systematic review of the literature. Lung Cancer (2013) 82(2):197-203. doi:10.1016/j.lungcan.2013.07.026

23. Tsao MN, Rades D, Wirth A, Lo SS, Danielson BL, Gaspar LE, et al. Radiotherapeutic and surgical management for newly diagnosed brain metastasis(es): an American Society for Radiation Oncology evidence-based guideline. Pract Radiat Oncol (2012) 2:210-25. doi:10.1016/j.prro.2011.12.004

24. Khalsa SS, Chinn M, Krucoff M, Sherman JH. The role of stereotactic radiosurgery for multiple brain metastases in stable systemic disease: a review of the literature. Acta Neurochir (Wien) (2013) 155(7):1321-7. doi:10.1007/s00701013-1701-5

25. Soon YY, Tham IW, Lim KH, Koh WY, Lu JJ. Surgery or radiosurgery plus whole brain radiotherapy versus surgery or radiosurgery alone for brain metastases. Cochrane Database Syst Rev (2014) 3:CD009454. doi:10.1002/14651858. CD009454.pub2 [Epub ahead of print].

26. Halasz LM, Rockhill JK. Stereotactic radiosurgery and stereotactic radiotherapy for brain metastases. Surg Neurol Int (2013) 4(Suppl 4):S185-91. doi:10.4103/2152-7806.111295

27. Wang XS, Rhines LD, Shiu AS, Yang JN, Selek U, Gning I, et al. Stereotactic body radiation therapy for management of spinal metastases in patients without spinal cord compression: a phase 1-2 trial. Lancet Oncol (2012) 13:395. doi:10.1016/S1470-2045(11)70384-9

28. Available from: http://www.rtog.org/ClinicalTrials/ProtocolTable/StudyDetails. aspx?study $=0631$

Conflict of Interest Statement: The Guest Associate Editor Vera Hirsh declares that, despite being affiliated to the same institution as author Sergio Faria, the review process was handled objectively and no conflict of interest exists. The author declares that the research was conducted in the absence of any commercial or financial relationships that could be construed as a potential conflict of interest.

Received: 08 May 2014; accepted: 08 August 2014; published online: 13 October 2014. Citation: Faria SL (2014) Role of radiotherapy in metastatic non-small cell lung cancer. Front. Oncol. 4:229. doi: 10.3389/fonc.2014.00229

This article was submitted to Thoracic Oncology, a section of the journal Frontiers in Oncology.

Copyright (C) 2014 Faria. This is an open-access article distributed under the terms of the Creative Commons Attribution License (CC BY). The use, distribution or reproduction in other forums is permitted, provided the original author(s) or licensor are credited and that the original publication in this journal is cited, in accordance with accepted academic practice. No use, distribution or reproduction is permitted which does not comply with these terms. 